\title{
Attendance at a breast screening clinic: a problem of administration or attitudes
}

\author{
K FRENCH, A M D PORTER, S E ROBINSON, F M MCCALLUM, J G R HOWIE, M M ROBERTS
}

\begin{abstract}
In a study of why a sample of women, aged 45-64 and registered with a group practice in Edinburgh, attended or did not attend the Edinburgh Breast Screening Clinic demographic, aetiological, social, and perceptual characteristics of attenders and non-attenders were compared. Similar proportions of attenders and non-attenders knew the chance of a breast lump being cancer and were aware of the benefits of early diagnosis and treatment. The study, however, suggests that non-attenders saw the screening clinic as a place of risk while the attenders saw screening in a positive light: $79 \%$ of non-attenders as compared with $36 \%$ of attenders said that they were afraid of cancer being found, and most women attended either to reassure themselves that they had not got breast cancer or to receive early treatment if they had. Furthermore, $72 \%$ of non-attenders as compared with $13 \%$ of attenders were anxious that their lives would be disrupted if cancer were found at the screening clinic. There may well be an important irreducible element to non-atten-
\end{abstract}

Department of Clinical Surgery, University of Edinburgh Medical School, Royal Infirmary, Edinburgh

$\mathrm{K}$ FRENCH, BA, research co-ordinator

S E ROBINSON, BA, SRN, research nurse

M M ROBERTS, BSC, MD, senior lecturer and director, Edinburgh Breast Screening Clinic

Department of General Practice, University of Edinburgh Medical School, Edinburgh

A M D PORTER, BA, MPHIL, lecturer

F M MCCALLUM, RGN, SCM, practice nurse

J G R HOWIE, MD, FRCGP, professor dance due to attitudinal factors; the ethical implications of attempting to eliminate this require careful consideration.

\section{Introduction}

Although there is evidence to suggest that the early diagnosis of breast cancer leads to an improvement in prognosis, the benefits of screening for the disease in asymptomatic women are still being evaluated. ${ }^{1}$ Reports of the Health Insurance Plan study in New York indicate an improvement in mortality over nine years in the group offered screening. ${ }^{2}$

In Britain, after several feasibility studies, ${ }^{3-5}$ a national programme involving women aged 45-64 years is currently in progress. ${ }^{6}$ In Edinburgh this takes the form of a randomised trial. Since 1979, all women in this age group in practices randomly allocated for screening have been invited to attend a screening clinic. The letter of invitation, computer produced, is from the director of the clinic, but the interest of the individual general practitioner is emphasised.

Clearly any benefit achievable by screening will be reduced if women do not respond to their invitation, or if the procedure is not acceptable to them. The feasibility study in Edinburgh ${ }^{5}$ had shown that $80 \%$ of women in selected practices attended at first visit, whereas in New York it was $65 \%{ }^{7}$ and in south Manchester $54 \%{ }^{8}$ Since 1979 , however, roughly two-thirds of the women invited in Edinburgh have attended for screening. It is important in terms of both the cost effectiveness and the ethics of this project to determine the reason why women do not take up the invitation for screening. In association with the university department of general practice, which had been randomly assigned for screening, it was decided to set up the study reported here.

The aim of the study was to investigate the reasons why women did not attend for breast screening and to compare their 
characteristics and their reasons for non-attendance with the characteristics and reasons for attendance of attenders in the same practice.

\section{Method}

Structured interview schedules were developed and piloted at the Edinburgh Breast Screening Clinic with attenders from other practices. It was not feasible to pilot the interviews with the non-attenders, but the wording of the two schedules was identical for demographic characteristics, knowledge and experience of breast disease, aspects of health behaviour, and home and work commitments. Information was also sought on factors important in the aetiology of the disease, reasons for attendance or non-attendance, and attitudes to and anxiety about screening. (Copies of the schedules used are available from the authors.) The schedules and the techniques of their administration were extensively discussed by the interviewers (KF, SR, FMcC) to minimise the possibility of bias.

The sample of attenders was drawn by randomly selecting a woman with an early appointment at the clinic and then approaching those women whose appointments fell at half-hourly interviews thereafter. Attenders were approached on arrival at the clinic and interviewed after screening but before the full results of their examinations were available.

There were three groups of non-attenders-women who wrote declining the invitation, women who confirmed that they would attend but did not, and those who made no response to the letter. The sample of each group drawn by random numbers was sent a letter explaining the purpose of the study and asking if the practice nurse (FMcC) could either visit them at home or see them at the practice.

\section{Results}

RESPONSE

Of the total practice population of 5000, 499 women aged 45-64 formed the basis of the study. Three months after the original appointment offered, 273 women had attended for screening ( $55 \%$ ) and 205 had not $(41 \%)$. Fifteen women (3\%) had died or moved away and six had postponed their appointments.

Of the 90 attenders sampled, $75 \%$ agreed to be interviewed but seven were lost to the study as there was no interviewer waiting when they emerged from screening. Thus 61 women $(22 \%$ of all attenders) were interviewed. Of the non-attenders sample, 54 women $(49 \%)$ agreed to be interviewed. This sample comprised $26 \%$ of all nonattenders. The age distribution was similar for both samples and closely mirrored the age distributions for all attenders and nonattenders. All percentages are calculated on the 61 attenders and 54 non-attenders, and the statistical tests were all $\chi^{2}$ (with Yates's correction factor) on the real numbers.

\section{DEMOGRAPHIC AND AETIOLOGICAL CHARACTERISTICS}

As shown in table I, the two samples were similar in age but slightly more of the non-attenders were single, widowed, divorced, or separated. There was a social class difference as $67 \%$ of attenders were manual working class as against $87 \%$ of the non-attenders $(p<0.05)$.

More women who attended for screening had a family history of breast cancer compared with the non-attenders, and slightly more were premenopausal or had undergone hysterectomy. On the other hand, although the numbers were small, it should be noted that twice as many non-attenders had had a previous breast complaint.

\section{KNOWLEDGE, BELIEF, AND EXPERIENCE OF BREAST DISEASE}

The two samples had several broadly similar beliefs: that early treatment always or usually made a difference to chances of survival (attenders $85 \%$, non-attenders $77 \%$ ), that breast lumps had a likelihood of $50 / 50$ or greater of being benign ( $90 \%, 91 \%$ respectively), and that breast lumps were a symptom of breast cancer $(91 \%, 81 \%)$. The samples had had similar exposure to programmes about breast cancer on television and to articles about it in newspapers or magazines. More attenders $(90 \%$ as against $61 \%)$, however, knew someone who
TABLE I-Demographic and aetiological factors in attenders and non-attenders

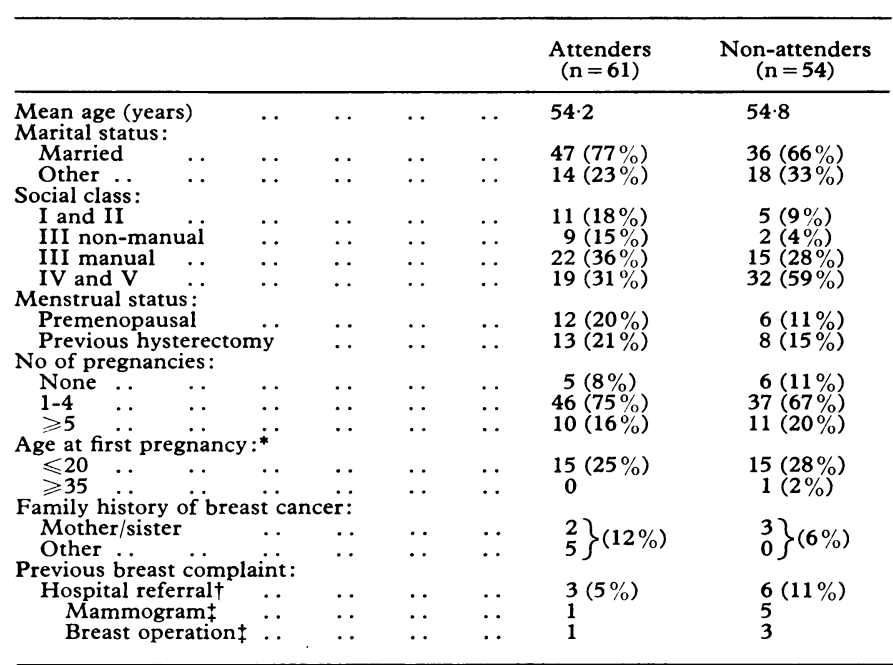

* Not known in every case.

†Excluding abscesses during lactation.

Included within hospital referral.

had had a breast lump, more attenders ( $87 \%$ as against $44 \%$ ) knew someone who had had breast cancer, and fewer attenders thought that pain was a symptom of breast cancer ( $11 \%$ against $48 \%$ ). These differences were significant at the 0.001 level.

\section{ASPECTS OF HEALTH BEHAVIOUR}

More attenders than non-attenders had had cervical smears $(84 \%$ as against $65 \%)$ and more had had smears at their own request $(20 \%$ as against $9 \%)$. Attenders were more likely to have regular dental check-ups (33\% as against $15 \%$ ) and were significantly more likely to have all or some of their own front teeth ( $52 \%$ as against $20 \%)$.

\section{REASONS FOR ATTENDING}

The 61 attenders gave 176 reasons for going to the screening clinic and these, together with the single most important reason given by each attender, are set out in table II. This table shows that, in order of importance, the main reasons for attendance were the desire to know or make sure that nothing was wrong (41\%) followed by "passive" reasons $(25 \%)$, the belief that screening would prevent disease $(15 \%)$ and the importance of early treatment $(10 \%)$. "Passive" reasons included statements such as:

"I didn't decide-I just got the letter."

"I didn't have any particular reason-the letter arrived and I thought why not?"

TABLE II-Reasons for attending screening clinic

\begin{tabular}{|c|c|c|}
\hline Reasons & $\begin{array}{c}\text { All reasons } \\
(\mathrm{n}=176)\end{array}$ & $\begin{array}{l}\text { Main reasons } \\
(\mathrm{n}=61)\end{array}$ \\
\hline \multicolumn{2}{|l|}{$\begin{array}{l}\text { Wishing to know: } \\
\text { Make sure nothing wrong, to find out, }\end{array}$} & $41 \%$ \\
\hline \multicolumn{3}{|l|}{$\begin{array}{l}\text { Passive reasons: } \\
\text { Sent by GP, got letter, didn't think, why }\end{array}$} \\
\hline "official". & $22 \%$ & $25 \%$ \\
\hline \multicolumn{3}{|l|}{ Prevention: } \\
\hline $\begin{array}{l}\text { a good opportunity } \\
\text { Importance of early treatment: }\end{array}$ & $16 \%$ & $15 \%$ \\
\hline $\begin{array}{l}\text { Importance of early treatment: } \\
\text { Early treatment cures, gives better } \\
\text { chances, catch it "in time," postponing } \\
\text { treatment means poor outlook }\end{array}$ & $15 \%$ & $10 \%$ \\
\hline \multicolumn{3}{|l|}{$\begin{array}{l}\text { Awareness and vulnerability: } \\
\text { Right age group, symptoms, breast }\end{array}$} \\
\hline $\begin{array}{l}\text { awareness, family history, possibility of } \\
\text { cancer, aware of cancer }\end{array}$ & $15 \%$ & $2 \%$ \\
\hline \multicolumn{3}{|l|}{ Miscellaneous: } \\
\hline $\begin{array}{l}\text { Only fair on family, screening better than } \\
\text { self examination, etc }\end{array}$ & $7 \%$ & $8 \%$ \\
\hline
\end{tabular}


"When my doctor sent for me-when he wants anything done I just go."

"I am a great believer in trying to help people that are trying to help you."

When asked if a decision to attend for screening had been influenced by a specific person, 20 of the attenders (33\%) agreed that they had been influenced by their general practitioner's "interest" in screening.

\section{REASONS FOR NON-ATTENDANCE}

The 54 non-attenders gave 95 reasons for not going to the screening clinic and these, together with the main reason given by each woman, are set out in table III. This table shows that the main reasons given in order of importance were practical difficulties (33\%), a lack of interest or the belief that screening was irrelevant $(26 \%)$, and fear $(22 \%)$ or "not feeling like it" ( $9 \%$ ). Only one woman mentioned the hazard of radiation dosage as a reason for non-attendance.

TABLE III-Reasons for not attending screening clinic

\begin{tabular}{lcc}
\hline Reasons & $\begin{array}{c}\text { All reasons } \\
(\mathrm{n}=95)\end{array}$ & $\begin{array}{c}\text { Main reasons } \\
\text { (n=54) }\end{array}$ \\
\hline $\begin{array}{l}\text { Practical reasons: } \\
\text { Away on holiday, work commitments, } \\
\text { family and health commitments, travelling } \\
\text { difficulties, poor physical health }\end{array}$ & & \\
$\begin{array}{l}\text { Not interested/irrelevance of screening: } \\
\text { Had enough of check-ups and hospitals, } \\
\text { been tested before, too old, can't be } \\
\text { bothered, feel quite well }\end{array}$ & $41 \%$ & $33 \%$ \\
$\begin{array}{l}\text { Fear: } \\
\begin{array}{l}\text { Can't face it, “feardy," distrust of } \\
\text { medicine, negative influence of others }\end{array}\end{array}$ & $24 \%$ & $26 \%$ \\
$\begin{array}{l}\text { Didn't feel like it } \\
\text { Other: } \\
\text { Forgot about it, not enough explanation } \\
\text { in letter, screening dangerous }\end{array}$ & $\begin{array}{c}17 \% \\
6 \%\end{array}$ & $\begin{array}{r}22 \% \\
9 \%\end{array}$ \\
\hline
\end{tabular}

\section{HOME AND WORK COMMITMENTS}

Although practical difficulties were more often presented by non-attenders, more of the attenders were working $(75 \%$ as against $57 \%$ ) and more were working full time (36\% as against $22 \%$ ). Furthermore, for $43 \%$ of attenders their working hours and clinic hours were mutually exclusive; this was the case for only $28 \%$ of nonattenders. Comparable proportions of the two samples had dependants living with them, but more of the attenders had other calls on their time, such as elderly relatives or grandchildren to feed. Nevertheless, when asked how easy it was to get away from either home or work commitments for a couple of hours during the day, more of the nonattenders, in both cases, said that they thought it was difficult (overall $44 \%$ as against $21 \%$ ). It should be noted that $41 \%$ of attenders had to change the time of their appointment in order to attend the clinic.

\section{FEAR AND ANXIETY}

Both attenders and non-attenders were asked if any factors on a check list about fear and anxiety relating to screening applied to them or not. The results of these questions are set out in table IV. The two

TABLE IV-Fear and anxiety related to screening

\begin{tabular}{|c|c|c|}
\hline Reasons & $\begin{array}{l}\text { Attenders } \\
(\mathrm{n}=61)\end{array}$ & $\begin{array}{c}\text { Non-attenders } \\
(\mathrm{n}=53) \dagger\end{array}$ \\
\hline $\begin{array}{l}\text { Feelings that one should not go looking for } \\
\text { trouble* } \\
\text { Fear of cancer being found } \\
\text { Anxiety about the trouble and bother entailed }\end{array}$ & $\begin{array}{r}7(11 \%) \\
22(36 \%)\end{array}$ & $\begin{array}{l}30(58 \%) \\
42(79 \%)\end{array}$ \\
\hline $\begin{array}{l}\text { if anything found }{ }^{*} \\
\text { Modesty and dislike of being examined } \\
\text { Anxiety about screening examination }\end{array}$ & $\begin{array}{l}8(13 \%) \\
8(13 \%) \\
18(30 \%)\end{array}$ & $\begin{aligned} 38(72 \%) \\
7(13 \%) \\
24(45 \%)\end{aligned}$ \\
\hline
\end{tabular}

* Significant at 0.001 level.

tOne non-response. samples were similarly anxious about the screening examination and had an equal modesty and dislike of being examined. The nonattenders, however, were significantly more likely to feel "one shouldn't go looking for trouble," were more afraid of cancer being found, and were more anxious about what would happen if cancer were found $(p<0.001)$. The attenders were asked why they thought some women did not attend for screening. Of the reasons thought of by them, $40 \%$ were fear, followed by avoidance of the problem $(17 \%)$ and ignorance, silliness, or feeling invulnerable (14\%). Only $11 \%$ of all comments acknowledged practical obstacles to attendance.

\section{Discussion}

The findings presented in this paper have to be interpreted cautiously. At first sight it may appear that the sample of nonattending women approached for interview was small and the number of refusals high. The size of the sample was determined by the belief of the research team that it would be wrong to expect accurate recall of reasons for and feelings about refusal later than Christmas when the original invitation to attend the clinic had been in September. This left eight interviewing weeks for one part-time research worker, and a maximum of only about 100 interviews was thought feasible. The non-attenders who did not agree to be interviewed were not pressed further for ethical reasons. It should be recalled that they had already declined one invitation to attend for screening and the approach we made in relation to this study was, in effect, already a second approach on a matter that (as our researchers had shown) creates real anxiety. Nevertheless, the still substantial refusal rate by non-attenders may have concealed important factors.

There is also a danger that the researchers made women think of reasons for non-attendance when in fact they have had no clear or specific reason. (For many practices, an important factor for women's non-attendance is the accuracy of health board lists of people registered with the general practices. In this study only $3 \%$ of letters of invitation were returned as "not known at this address." This rate of return is considerably lower than the average rate for practices.)

More women who attended for screening said that they had more work or home commitments, or both, but more non-attenders said that they had found it difficult to get away from their commitments. Two particular responses that non-attenders raised-the feeling that "you shouldn't go looking for trouble" and the anxiety about the trouble and bother there would be if anything was found-seemed to match their perceived difficulties with their commitments.

For the non-attenders, the screening clinic seemed to be seen as a place of risk; over three-quarters of non-attenders said that they had been afraid that cancer would be found. The attenders also largely attributed non-attendance to fear.

Even though over half the attenders had been anxious about screening and one-third admitted-after the event-that they had been afraid of cancer being found, the attenders seemed, on the whole, to see screening in a positive light. Two of the main reasons for going to the clinic cited by attenders had been for the reassurance that they had not developed the disease, and that they would have' gained the benefits of early treatment if they had.

Apart from the non-attenders' belief that pain was a symptom of breast cancer, the two samples were equally informed about the disease. The attenders may have felt more vulnerable or aware of breast cancer as more of them knew women with the disease. Nevertheless, more of the non-attenders had experienced breast problems in the past. Possibly their experiences "put them off" further voluntary investigation. An alternative explanation is that they had thought nothing could be wrong with their breasts because they had been previously reassured, and any further investigation would be unnecessary.

It seems unlikely, however, that there is a single motivating factor that differentiates between the samples; the attenders accorded awareness and vulnerability as of little overall importance. More importantly, attendance and non-attendance for 
breast screening was consistent with the women's previous health behaviour.

\section{Implications}

It is difficult to be confident when commenting on an area as subjective as motivation, but whether due to personal, social, or cultural characteristics, the differences between attenders and non-attenders with regard to commitments, previous health behaviour, anxiety, and fear are so substantial as to suggest that they did not occur by chance.

The study reported here suggests that there are women who are unlikely to attend for breast (or any) screening. To do so would be out of character with their previous health behaviour, and they are further disinclined both by fear and by their perception of their home and work commitments. It seems from this research that the overall uptake rate reflects women's attitudes rather than their practical commitments. We do not know whether improved factual knowledge of breast disease would lead to a greater acceptance of screening, but we do recognise that attitudes and patterns of behaviour are difficult to change. The non-attendance rates may not be reducible without putting pressures on patients that would be widely regarded as unacceptable, given the present uncertainty over the long-term benefits of a screening programme.
The department of general practice is grateful for financial support from the Scottish Health Education Group.

This study was made possible by a grant from the Cancer Research Campaign to one of us (MMR).

\section{References}

1 Anonymous. Early diagnosis and survival in breast cancer. Lancet 1981; ii:785-6.

2 Shapiro S. Evidence on screening for breast cancer from a randomised trial. Cancer $1977 ; 39: 277-82$.

${ }^{3}$ Chamberlain J, Roger P, Price JL, Ginks S, Nathan BE, Burn I. Validity of clinical examination and mammography as screening tests for breast cancer. Lancet 1975;ii:1026-30.

4 George WD, Gleave EN, England PC, et al. Screening for breast cancer. Br Med F 1976;ii :858-60.

${ }^{5}$ Edinburgh Breast Screening Clinic. Screening for breast cancer. Br Med $\mathcal{F}$ 1978 ;ii:175-8.

6 Department of Health and Social Security Working Group. Trial of early detection of breast cancer: description of method. Br $\mathcal{F}$ Cancer 1982; 44:616-27.

${ }^{7}$ Fink R, Shapiro S, Lewison J. The reluctant participant in a breast cancer screening programme. Public Health Rep 1968;83:479-90.

${ }^{8}$ Hobbs P, Smith A, George WD, Sellwood RA. Acceptors and rejectors of an invitation to undergo breast screening compared with those who referred themselves. $\mathcal{F}$ Epidemiol Community Health 1980;34:19-22.

(Accepted 23 fune 1982)
Three brothers, aged 12,10, and 8, all have juvenile diabetes. There is no family history of the disease. Is it common for siblings to be affected?

There is certainly a strong genetic component in the aetiology of type I insulin-dependent diabetes, although studies on identical twins have shown that for type I diabetes, in contrast to type II, they may be discordant in respect of diabetes for very many years. ${ }^{1}$ This emphasises the importance of other agents, such as virus illnesses and diabetogenic dietary factors. ${ }^{2}$ Where more than one sibling has type I diabetes they tend to be of similar HLA tissue types. The occurrence in three siblings of one family with neither parent being affected would suggest that one relevant haplotype was inherited from each parent, thus accounting for the greater susceptibility to diabetes of these children. ${ }^{3}$ In the Birmingham Diabetes Survey $4 \cdot 8 \%$ of siblings of diabetics aged up to 29 also had diabetes, whereas the figure was only $0.4 \%$ in the controls. ${ }^{4}$-J M STOWERS, professor of diabetes and endocrinology, Aberdeen. 1 Pyke DA, Nelson PG. Diabetes mellitus in identical twins. In: Creutzfeldt W,
Köbberling J, Neel JV, eds. The genetics of diabetes mellitus. Berlin: SpringerVerlag, 1976.

2 Helgason T, Jonasson MR. Evidence for a food additive as a cause of ketosis-prone diabetes. Lancet 1981 ;ii:716-20.

Walker A, Cudworth AG. Type I (insulin-dependent) multiplex families; mode of genetic transmission. Diabetes 1980;29:1036-9.

orking Party appointed by the College of General Practitioners. The family
history of diabetes. $\mathrm{Br}$ Med $\mathcal{f} 1965 ; \mathrm{i}: 960-2$.

Is there any risk of an amateur engaged in glass engraving developing silicosis? He uses various types of glass with a modified dentist's drill as an engraving tool. What reasonable precautions should he take?

Glass contains silicates with no free silica. There is no risk of developing silicosis, and glass dust is classified as a nuisance dust. ${ }^{1}$ Some glasses used for engraving may contain up to $33 \%$ lead. There is thus a potential hazard, although whether it exists for the amateur is difficult to say. A study a few years ago of some professional glass cutters showed some raised blood lead concentrations. ${ }^{2}$ Noise is another hazard from glass engraving, and this might be quite pronounced with the face held close to a dentist's drill. Ear muffs are sometimes used by amateur glass engravers. It is not clear from the question whether the engraving is being done wet or dry. If the former then the dust would probably be removed as a slurry. If the engraving is done dry, however, then the glass dust might be a general irritant, particularly to the eyes. It is unlikely that the subject would want to wear safety goggles, for he would want to watch the work closely without any optical distortion. Furthermore, the hazard would be from a nuisance dust and not from sharp glass. Therefore, his ordinary spectacles or even good safety spectacles with a plain lens should be sufficient.-W R LEE, professor of occupational health, Manchester. 1 Patty FA, ed. Industrial hygiene and toxicology. Vol 2. 2nd revised ed. New York:
Interscience Publishers, $1967: 2270$.
2 Finch WM. Lighting for the cutting of crystal glass : a comparison and analysis of
conditions in two factories, and an investigation into possible improvements.
Manchester: University of Manchester, 1981. (MSc thesis.)

Are depression or behavioural changes recognised side effects of long-term administration of oral contraceptives containing ethinyloestradiol and levonorgestrel?

Any combined oral contraceptive preparation may cause depression, anxiety, or loss of libido. It has been suggested ${ }^{12}$ that the cause may be altered tryptophan metabolism, and also that there is a relationship between depression and endometrial monoamineoxidase activity. These suggestions remain unconfirmed, and there may be other factors. ${ }^{1}$ With older types of oral contraceptive the incidence of mild depression may be as high as $10-20 \%$ in the first months of use, but this quickly decreases with time. The Royal College of General Practitioners Survey in 1974 found no increased incidence of severe depression. Among patients taking newer oral contraceptives containing ethinyloestradiol and levonorgestrel behavioural effects do occur: one study reported "nervousness" and loss of libido in $4.5 \%$ of patients, but it is not clear whether these investigators asked specifically about depression. Circulating androgen concentrations (which may be related to libido in v:omen) seem to be lower ${ }^{4}$ among women taking this type of contraceptive, but the relation between androgens and sexuality is not a simple one. The difficulty of assessing psychological side effects is illustrated ${ }^{2}$ by the high incidence of loss of libido and nervousness reported by women taking placebo in the guise of oral contraceptives. - JAMES OWEN DRIFE, lecturer in obstetrics and gynaecology, Bristol.

1 Hawkins DF, Elder MG. Human fertility control. London: Butterworth, 1979. Andrews WC. Oral contraception. Clin Obstet Gynaecol 1979;6:3-26.

Briggs MH, Briggs $M$. Clinical and biochemical investigations of a variable-dose combined type oral contraceptive. Curr Med Res Opinion 1977;5:213-6.

Bancroft J, Davidson DW, Warner $P$, Tyrer $G$. Androgens and sexual behaviour in women using oral contraceptives. Clin Endocrinol 1980;12:327-40. 